\title{
Resenha \\ Bounding Power: \\ Republican Security Theory from the Polis to the Global Village*
}

Daniel H. Deudney. Princeton, Princeton University Press, 2007, 391 páginas.

João A. C. Vargas**

\begin{abstract}
A produção acadêmica no campo de teoria das Relações Internacionais não consiste, na sua maior parte, em "novas teorias". Nos principais livros e periódicos da área, o que se encontra não são, de modo geral, tentativas de se reinventar a roda, mas um esforço coletivo e gradual de acumulação de conhecimento e aperfeiçoamento teórico. À medida que se ampliam os poderes explicativos e capacidades interpretativas dos modelos teóricos já existentes, espera-se que eles serão instrumentos cada vez mais valiosos para compreender uma realidade internacional que adquire constantemente novas complexidades.
\end{abstract}

Contudo, de tempos em tempos, o campo depara-se com uma obra cuja criatividade e determinação de "começar do início" do processo

\footnotetext{
*Resenha recebida em janeiro e aprovada para publicação em março de 2007.

**Diplomata e mestrando em Relações Internacionais na Universidade de Brasília (UnB). As opiniões aqui expressas são de caráter pessoal e não refletem necessariamente aquelas do Ministério das Relações Exteriores ou do governo brasileiro.
}

CONTEXTO INTERNACIONAL Rio de Janeiro, vol. 29, nํㅡ 2, julho/dezembro 2007, p. 435-441. 


\section{Resenha}

de teorização reconfigura o debate. Tal façanha já foi empreendida por autores como Kenneth Waltz, Alexander Wendt, Nicholas Onuf e agora, talvez, também por Daniel Deudney.

Deudney é um autor estabelecido no campo, embora pouco conhecido no Brasil, que já publicou diversos artigos e alguns livros sobre matérias tão diversas quanto meio ambiente, espaço exterior, armas nucleares e ordem internacional. Bounding power é, porém, sua mais importante obra até o momento, sintetizando e amarrando vários temas que têm surgido nos seus escritos ao longo dos anos.

O livro é escrito como uma reconstrução da tradição que o autor denomina de "teoria de segurança republicana", surgida na Antiguidade e esquecida em meio aos debates teóricos de Relações Internacionais do século XX. Deudney argumenta que o realismo e o liberalismo - e, embora menos diretamente, o construtivismo - representam fragmentos da teoria de segurança republicana. Ao empreender a reconstrução desta "teoria-mãe", Deudney propõe uma teoria que incorpora largas seções do pensamento realista e liberal a uma estrutura mais ampla, dando-lhes maior coerência e fôlego explicativo.

Antes de continuar, é mister notar as diferenças entre a obra de Deudney e o esforço de Onuf (em The republican legacy in international thought) de resgatar o pensamento republicano. Enquanto Onuf vê no republicanismo uma tradição de pensamento político voltado para os conceitos de comunidade e virtude, que se viu suplantado pelo liberalismo nos séculos XVIII e XIX, Deudney enxerga-o como sendo uma tradição voltada para o problema concreto de simultaneamente garantir a liberdade política e preservar a segurança contra violência física. Embora não sejam abordagens francamente contraditórias, as significativas diferenças de foco tornam suas empreitadas mais paralelas do que convergentes. Ambas, contudo, ressaltam a necessidade de se resgatar uma veia rica de pensamento que caiu na 


\section{Resenha}

obscuridade, e apontam a relevância desse pensamento para a teorização sobre Relações Internacionais.

Deudney vê a tradição republicana em termos essencialmente materialistas (ele diz partir de uma ontologia híbrida, em vez de puramente materialista ou idealista, mas não desenvolve esse ponto). Para ele, a república é uma forma "negárquica" de organização política (um dos diversos termos cunhados ao longo da obra, a "negarquia" seria uma alternativa à anarquia e à hierarquia, em que as unidades são organizadas por meio de restrições e contrapesos que as ordenam sem as hierarquizar), destinada a preservar a segurança física de seus participantes sem lhes tolher a liberdade política. Serve para proteger os atores dos perigos, tanto domésticos quanto internacionais, da anarquia e da hierarquia. A possibilidade da existência de repúblicas, e o formato e extensão dessas, evoluem à medida que os contextos materiais se transformam, isto é, à medida que a evolução tecnológica aumenta as capacidades de transporte e comunicação sobre longas distâncias e incrementa o que o autor chama de "interdependência da violência", a capacidade dos atores de causarem dano uns aos outros.

A teoria republicana de segurança teria, portanto, duas problemáticas centrais. A primeira, apropriada pelo realismo, trata da anarquia e da interdependência. Ela envolve a construção de estruturas que dirimem a anarquia intolerável, isto é, aquela anarquia que, dado o contexto material em qualquer época, representa uma ameaça à sobrevivência dos atores. À medida que a tecnologia avança e a interdependência da violência cresce, o âmbito da anarquia tolerável diminuirá; por exemplo, a unidade política capaz de garantir a segurança na época do arco e da flecha será insuficiente com o surgimento da pólvora. A segunda problemática central é a do controle da hierarquia. As formas de governos hierárquicas, não sendo sujeitas a controles e restrições, podem, por meio do abuso do poder e da repressão governamental, apresentar uma ameaça tão grande quanto a anarquia à liberdade política e segurança física. 


\section{Resenha}

A república surge, portanto, na Antiguidade, como uma espécie de polis dedicada a salvaguardar a liberdade política de seus cidadãos e protegê-los dos efeitos da anarquia. Ela seria, contudo, uma espécie particularmente vulnerável, sujeita ao que o autor chama de "leis de ferro do republicanismo das polis". A primeira lei afirma que, necessitando serem pequenas de modo a permitir o governo pelo povo, as polis republicanas eram particularmente sujeitas à conquista, devendo, portanto, manter-se constantemente em um estado de prontidão militar, o que levaria à erosão das liberdades individuais. Desta forma, as repúblicas só poderiam surgir em circunstâncias geográficas vantajosas, que facilitassem a defesa contra inimigos maiores. A segunda lei de ferro, baseada na experiência da república romana, afirmava que a polis republicana que buscasse garantir a sua segurança por meio da expansão territorial passaria a necessitar de um exército permanente no lugar de uma milícia cidadã. Esse exército, contudo, levaria quase inevitavelmente à derrubada da república e à instauração da ditadura.

As limitações de espaço não permitem resumir aqui toda a história que Deudney faz da teoria de segurança republicana das suas origens clássicas até o presente. É importante, contudo, citar pelo menos alguns dos passos e momentos mais fundamentais.

O desenvolvimento da tecnologia marítima, a partir da Renascença, permitiu o surgimento das repúblicas marítimas, como Veneza, Inglaterra e Holanda, cuja defesa não exigiria um exército permanente ou uma milícia cidadã, mas sim uma esquadra. Uma vez que o poder marítimo, utilizado para defender a república, não se prestava à repressão interna, ele permitia que as repúblicas se defendessem sem incorrer no risco de se tornarem ditaduras, e dispensava uma milícia, permitindo aos seus habitantes que eles se dedicassem ao comércio e à acumulação de riqueza.

Com o tempo, surgiu, também, a visão de Europa como república, que contrastava o grande número de pequenos Estados na Europa 
com os impérios grandes, mas pouco numerosos da Ásia. Os numerosos Estados europeus mantinham sua independência em virtude da combinação de três fatores: divisão (as barreiras geográficas à expansão, como cordilheiras e mares), equilíbrio (a ausência de um poder preponderante no sistema) e mistura (a interação entre poder terrestre e naval). Assim, no ponto em que a Escola Inglesa enxerga uma "sociedade internacional" constituída por valores compartilhados e o realismo vislumbra um equilíbrio de poder entre unidades estanques, Deudney aponta uma estrutura negárquica, possibilitada fundamentalmente pelo contexto material (tecnológico e geográfico) da época e da região.

O próximo grande momento da evolução da teoria de segurança republicana foi a fundação dos Estados Unidos, no chamado "sistema de Filadélfia”. O autor afirma que a Constituição de 1787, longe de criar um Estado hierárquico, criou uma forma inovadora de república, capaz de assegurar as liberdades individuais e defender a coletividade de ataques estrangeiros, ao mesmo tempo que preservava a estrutura contra o desmoronamento (anarquia) ou a tirania (hierarquia). Baseando-se principalmente no texto de $\mathbf{O}$ federalista, Deudney apresenta os Estados Unidos não como uma nova unidade no sistema westphaliano, mas como um sistema alternativo. $\mathrm{O}$ autor traça a derrocada do sistema de Filadélfia e sua substituição por um Estado federal nos escombros da Guerra da Secessão, mas mantém que a experiência norte-americana e os escritos de Hamilton, Madison e Jay sobre a teoria de segurança republicana constituem um marco mais relevante na teoria e prática das relações internacionais dos últimos séculos do que Kant e a teoria da paz democrática. O livro afirma que o (controvertido) êxito empírico da teoria da paz democrática pode ser explicado pela raridade de democracias do sistema internacional, e que a sobrevivência de repúblicas em face dos desafios do século XX se deve fundamentalmente à sua defesa pelo poderio norte-americano, poderio este conquistado a partir dos preceitos da teoria de segurança republicana. 


\section{Resenha}

Chegando à Revolução Industrial, o livro examina o trabalho de diversos autores - geopolíticos, idealistas, federalistas, socialistas, fascistas - e enxerga neles respostas diversas aos problemas apresentados pelos processos conjuntos de industrialização e globalização. As obras de autores como Mahan, Mackinder, Wells e Dewey são citadas para sustentar, convincentemente, que o período do fim do século XIX até meados do século XX assistiu não a um abandono, mas a uma revitalização e revolução da teoria de segurança republicana, que buscava se adaptar ao novo contexto material de um mundo em que a interdependência da violência e a integração em termos de comunicação e transporte haviam alcançado níveis nem mesmo sonhados anteriormente.

No último capítulo do livro, o autor busca explorar as transformações do sistema internacional ocasionadas pelo surgimento de armas nucleares. Após explorar cinco vertentes de pensamento acerca das implicações políticas das armas atômicas ("um-mundismo" nuclear, estrategismo nuclear, dissuasão estatista automática, dissuasão estatista institucional e "um-mundismo" nuclear federal-republicano), ele faz uma análise pormenorizada da última vertente, evolução do pensamento republicano para a nova era. Segundo ele, ao mesmo tempo que o desaparecimento dos Estados é altamente improvável por causa da relutância dos mesmos em cederem sua soberania a um governo mundial e pela dificuldade de se empreender com êxito uma campanha de conquista territorial global, o surgimento de armas nucleares criou uma situação de interdependência de violência intolerável - os Estados estão todos demasiadamente vulneráveis à aniquilação atômica. A solução para esse dilema seria a constituição de estruturas internacionais de controle conjunto das armas nucleares, que não fossem, contudo, dotadas das características de um governo mundial, como monopólio da força. Esta "república global" (cuja curta descrição aqui não faz jus ao pensamento de Deudney) preservaria a soberania estatal ao mesmo tempo que eliminaria a ameaça destrutiva da guerra nuclear. 
O autor não é, contudo, otimista em relação às perspectivas futuras do sistema internacional e da segurança republicana. Apontando para as transformações domésticas sofridas pelos Estados Unidos desde os ataques de 11 de setembro de 2001, ele afirma que, se não forem constituídas estruturas internacionais capazes de controlar a proliferação de armas de destruição em massa entre atores estatais e não estatais, as repúblicas serão cada vez mais forçadas a adotarem estruturas hierárquicas para se defenderem, com efeitos nefastos para os direitos individuais e liberdades políticas. Assim, mesmo que as armas atômicas não levem a uma catástrofe militar, podem trazer conseqüências irreversíveis para a preservação da democracia e do Estado de Direito no mundo.

Bounding power é um livro ousado de um autor audacioso. Deudney não tem pudor de cunhar diversos termos e neologismos a cada capítulo para abarcar os conceitos que utiliza. Ele escreve de forma clara e apresenta inúmeros quadros e figuras ao longo do texto para facilitar a sua compreensão. Sua releitura de séculos de escritos políticos à luz da teoria republicana, embora pareça ambiciosa à primeira vista, fundamenta-se em uma pesquisa ampla e cuidadosa. Seu diagnóstico da situação global atual pode ser considerado tanto alarmista quanto idealista, mas é apresentado de forma racional e coerente. Deudney lança um desafio aos teóricos de Relações Internacionais ao afirmar que o realismo e o liberalismo são "filhos mancos" da teoria da segurança republicana por descartarem a importância da preservação de liberdades domésticas e ignorarem a importância de fatores geográficos e tecnológicos, enquanto castiga o construtivismo por negligenciar fatores materiais que, propriamente compreendidos, seriam imprescindíveis para a compreensão e a explicação dos fenômenos internacionais. Apesar dos possíveis excessos e negligências do autor, é um desafio que merece ser aceito, e que tem o potencial de revitalizar a discussão teórica acerca das relações internacionais. 